\title{
Positive Efficiency of Combine Immunotherapy in Immunocompromised Girls with Recurrent Nonspecific Chronic Vulvovaginitis
}

Nesterova $\mathrm{IV}^{1,2}$, Kovaleva $\mathrm{SV}^{1}$, Chudilova $\mathrm{GA}^{1}$, Lomtatidze $\mathrm{LV}^{1}$, Krutova $\mathrm{VA}^{1}$, Shuvalov $\mathrm{AN}^{{ }^{3}}$ and Malinovskaya $\mathrm{VV}^{3}$

${ }^{1}$ Kuban State Medical University, Krasnodar, Russia

${ }^{2}$ People's Friendship University of Russia, Moscow, Russia

${ }^{3}$ Gamaleya Scientific and Research Centre of Epidemiology and Microbiology of the Ministry of Health of the Russian Federation, Moscow, Russia

${ }^{*}$ Corresponding author: Shuvalov AN, Gamaleya Scientific and Research Centre of Epidemiology and Microbiology of the Ministry of Health of the Russian Federation, Moscow, Russia, Tel: 89163475487, E-mail: Shuvalovan33@mail.ru

Citation: Nesterova IV, Kovaleva SV, Chudilova GA, Lomtatidze LV, Krutova VA, et al. (2018) Positive Efficiency of Combine Immunotherapy in Immunocompromised Girls with Recurrent Nonspecific Chronic Vulvovaginitis. J Gynecol Res 4(2): 207. doi: 10.15744/2454-3284.4.207

Received Date: August 01, 2018 Accepted Date: September 05, 2018 Published Date: September 07, 2018

\begin{abstract}
Nonspecific chronic vulvovaginites (NCVV) are a frequent clinical sign of immune deficiency, especially in young girls. The established problems with the functioning of various parts of the immune system (IS) in this pathology dictate the need to include immunomodulatory therapy into the complex. The developed program of combined immunotherapy for immunocompromised girls allows reducing the severity and duration of exacerbation of NCVV, their frequency against the background of a significant reduction in ARVI incidence. Positive clinical effects were observed with underlying restoration in IS functioning. A protective effect was obtained (observation in a catamnesis for 1 year): the duration of a clinically safe period increased from 6 to 11-11.5 months per year.
\end{abstract}

Keywords: Immunocompromised Girls; Immunotherapy; Vulvovaginitis

\section{Introduction}

Vulvovaginitis takes the first place in the structure of gynaecological disorders in girls of primary school age and preschool age, with the peak share at the age of 2-7 years old. Acute and chronic genital inflammations in childhood may later cause serious infections and inflammations in women of various ages and result in reproductive disorders in women of childbearing age. Therefore tackling the challenge of protecting the reproductive health of children and teenagers, preventing and treating gynaecological disorders in children is a burning issue; it is of huge practical significance and of a certain interest both for scientists and practitioners.

At the age of 2 to 7 years old the immune protective mechanisms develop functionally, and they may cause immune system (IS) malfunctions under the influence of frequent ARVI, dysbiotic mucous disorders, functional disorders in organs and systems, chronic somatic and endocrine pathologies accompanied with immune deficiency - immunocompromised children [1,2]. One of the clinical signs in immunocompromised children of this age is nonspecific chronic vulvovaginitis (NCVV). Any reduction in the responsiveness of a child's body which most often appears in girls with chronic genital inflammations or after any acute disorders of any localisation leads to vagina flora population disruption [3,4]. Over $60 \%$ of vulvovaginitis in girls of primary school age and preschool age are recurrent and are caused by extragenital pathology aggravation. Sometimes the reason for concern is a continuous inflammation with short periods of remission, resistance, or short or minimal improvement from traditional therapy. Sometimes it is hard to interpret the results of examinations, thus causing underestimation of the risk of various factors for the health of the growing organism. NCVV facilitates formation of synechia, cicatrical changes in vagina, manifestation or progression of allergies and thus reproduction disorders [5-9]. Besides, recurrent vulvovaginitis are usually associated with inadequate therapy of both NCVV and extragenital pathology.

Search for new therapies is based on the experience of gynaecologists with older patients. But the existing treatment standard targets primarily the main symptoms and ethiopathogenetic causes of recurrent NCVV to a lesser extent; and its immunonosotropic characteristics are not taken into account at all. Such therapy is hardly useful for girls $[7,9,10]$. Therefore specification of NCVV 
immunopathogenesis in girls and elaboration of rational immune therapy methods are of interest.

\section{Objective}

To develop an efficient program of combined immunotherapy for treatment of immunocompromised girls suffering from recurrent NCVV taking into account reviewed disorders in immune and interferon systems functioning.

\section{Materials and Methods}

We observed 25 girls of 3 to 4 years old suffering from recurrent active NCVV. The control group comprised 12 conditionally healthy girls of the respective age. Clinical, laboratory examinations and immune diagnostics were performed. In order to assess the immune system condition, we used immunophenotyping of T-, B- lymphocytes, natural killer cells (NKC). Phagocytal and microbicidal function of neutrophilic granulocytes (NG) was examined with determination of the number of actively phagocytizing NGs (actively phagocytizing NG PAN\%, phagocyte number - PN, phagocyte index - PI) and digestive activity (\% digestion - \%D and digestion index - ID). NADPH oxidase activity of NGs was determined using NBT test results (spontaneous and induced) (St. aureus); \% of formazan- positive NGs (\%FPC), the average cytochemical index (SCI), was taken into account; the \%FPCst/\%FPIsp ratio was used to calculate the coefficient of mobilisation (CM). ELISA methods were used to test serum $\operatorname{IgA}, \operatorname{IgM}, \operatorname{IgG}, \operatorname{IgE}$, IFNa, IFN $\gamma$ (test systems manufactured by Vektor-Best LLC, Novosibirsk). Statistical data processing was performed using StatSoft Statistica 6.0. The results were presented as the median with the upper and lower quartile (Me [Q1; Q3]). The non-parametric tests were used to compare groups in terms of quantitative characteristics: Mann-Whitney test and Wilcoxon test. The differences between groups were statistically significant with $\mathrm{p}<0.05$.

\section{Results and Discussion}

Out of 25 examined girls suffering from recurrent active NCVV there were 14 girls with criterial clinical signs of immunodeficiency: recurrent ARVI occurring more than 10 times per year, frequent NCVV aggravations [8,12]. Analysis of the IS and INF system in these patients made it possible to determine some problems with their functioning: proven reduction in the absolute number of $\mathrm{CD}^{+} \mathrm{CD}^{+-}$lymphocytes $\left(0.9[0.83 ; 1.02] \times 10^{9} / \mathrm{L}\right.$ vs.

$1.38[0.91 ; 1.63] \times 10^{9} / \mathrm{L}$ in control group, $\left.\mathrm{p}<0.05\right)$, CD3 ${ }^{-} \mathrm{CD} 16^{+} \mathrm{CD} 56^{+}-$lymphocytes $(0.33$ [0.24; 0.37] x109/L vs. 0.43 [0.31; 0.48] $\mathrm{x} 10^{9} / \mathrm{L}$ in control group, $\mathrm{p}<0.05$ ) in girls with NCVV vs control group (Figure 1 ). With underlying proven reduction in the absolute number of CD3 ${ }^{-C D} 19^{+-}$lymphocytes $\left(0.62[0.52 ; 0.71] \times 10^{9} / \mathrm{L}\right.$ vs. $1.01[0.95 ; 1.24] \times 10^{9} / \mathrm{L}$ in control group, $\left.\mathrm{p}<0.05\right)$, we have found out significant 2 -fold reduction in serum $\operatorname{IgA}(\mathrm{p}<0.05)$ and $\operatorname{IgG}(\mathrm{p}<0.05)$ and 1.5 -fold Reduction in the concentration of $\operatorname{IgM}$ $(\mathrm{p}<0.05)$ (Figure 1 and 2).

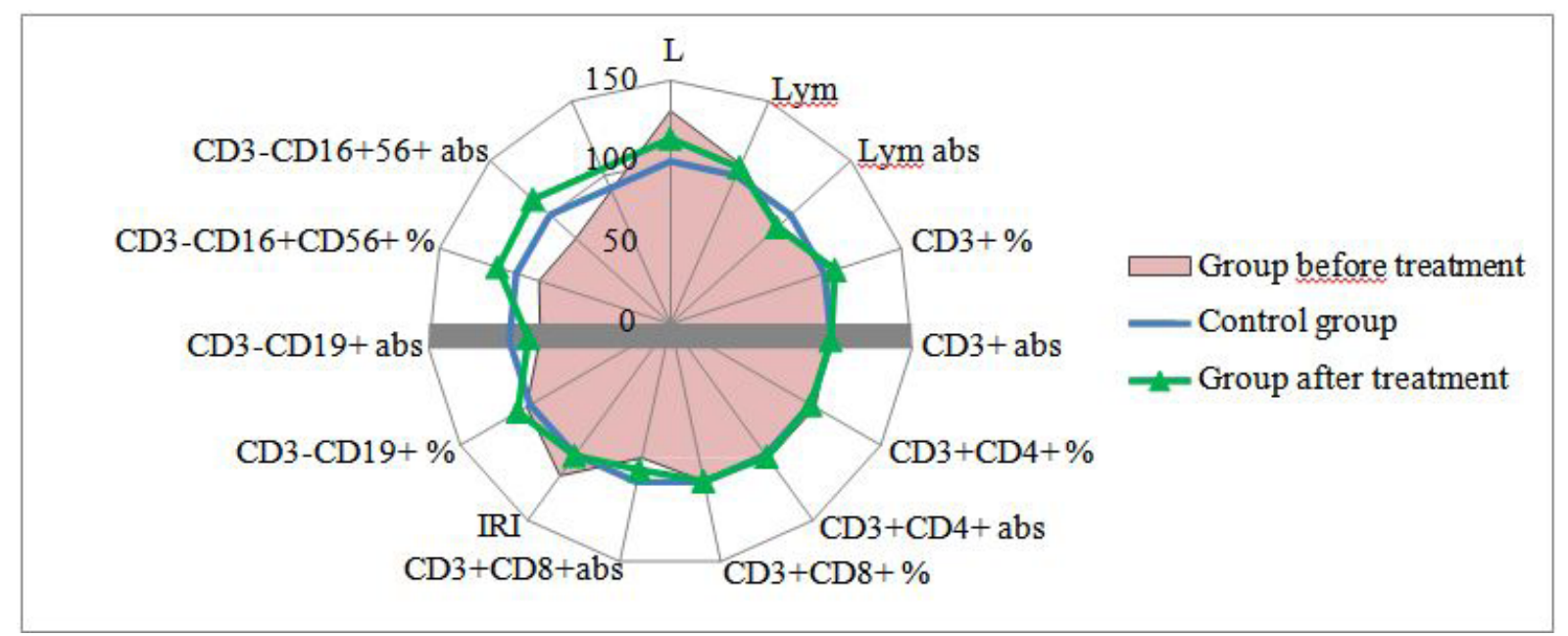

Figure 1: Cell-mediated immunity in immunocompromised girls suffering from recurrent NCVV with underlying combined immunotherapy (percent of the control group)

Figure 1 shows that before the treatment, immunocompromised girls with recurrent NCVV showed a decrease in T killers $\left(\mathrm{CD}^{+}{ }^{+} \mathrm{CD} 8^{+} \mathrm{abs}\right)$, NK cells (CD3-CD16 ${ }^{+} \mathrm{CD} 56^{+} \%$, CD3 ${ }^{-} \mathrm{CD} 16^{+} \mathrm{CD} 56^{+}$abs.), and B lymphocytes (CD3-CD19 + abs). After the treatment, the number of killers (T killers, NK cells) and B lymphocytes was restored.

Figure 2 shows the decrease in serum IgA, IgG, IgM levels in immunocompromised girls with Recurrent NCVV, and after the treatment the level of serum immunoglobulins (IgA, IgG, IgM) Was restored to the control. 


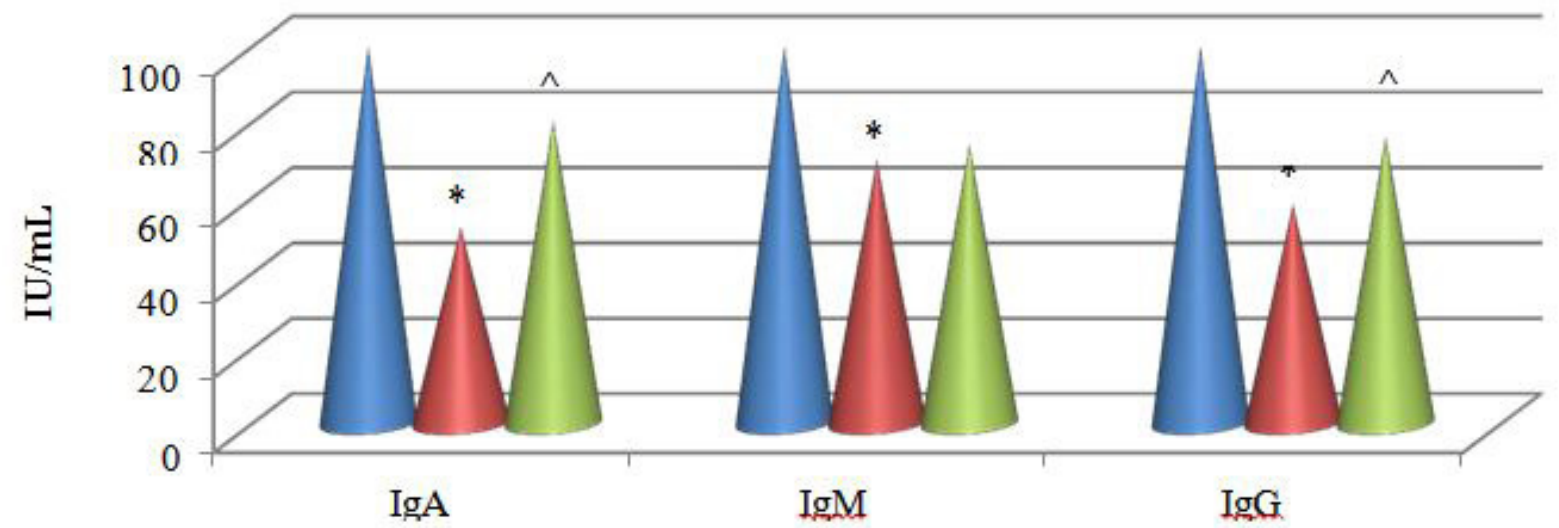

\footnotetext{
Control group $\quad$ Group before treatment $\quad$ Group after treatment

Note: ${ }^{*} \mathrm{p}<0.05$ - statistical significance vs. control group; ${ }^{\wedge} \mathrm{p}<0.05$ - statistical significance of the posttherapy group vs. pre-therapy group.

Figure 2: Antibody-mediated immunity (serum $\operatorname{IgA}, \operatorname{IgM}, \operatorname{IgG}$ ) in immunocompromised girls suffering

from recurrent NCVV with underlying combined immunotherapy (percent of the controlgroup)
}

Reduction in the main classes of immunoglobulins may be associated with shifting of B lymphocytes to IgE synthesis, accompanies by signs of atopic dermatitis, atopic vulvovaginitis. Reduction in IgA levels facilitates increased permeability of mucosa for allergenic agents, thus causing antigenemia, increased reaginic antibody titer (IgE, IgG4). Analysis of serum IgE levels in girls suffering from atopic dermatitis made it possible to Form 2 sub-groups: sub-group 1 (64\% of cases) where serum IgE level did not significantly differ from control parameters ( $\mathrm{p}>0.05)$; and sub-group 2 (36\% of cases) which was characterised by high IgE levels considerably exceeding control values: $112.51[96.4 ; 172.2] \mathrm{IU} / \mathrm{mL}$ vs. $26.83[10.4 ; 38.3] \mathrm{IU} / \mathrm{mL}(\mathrm{p}<0.05)$ (Figure 3 ). It is worth mentioning that $64 \%$ of observed girls with NCVV had atopic dermatitis.

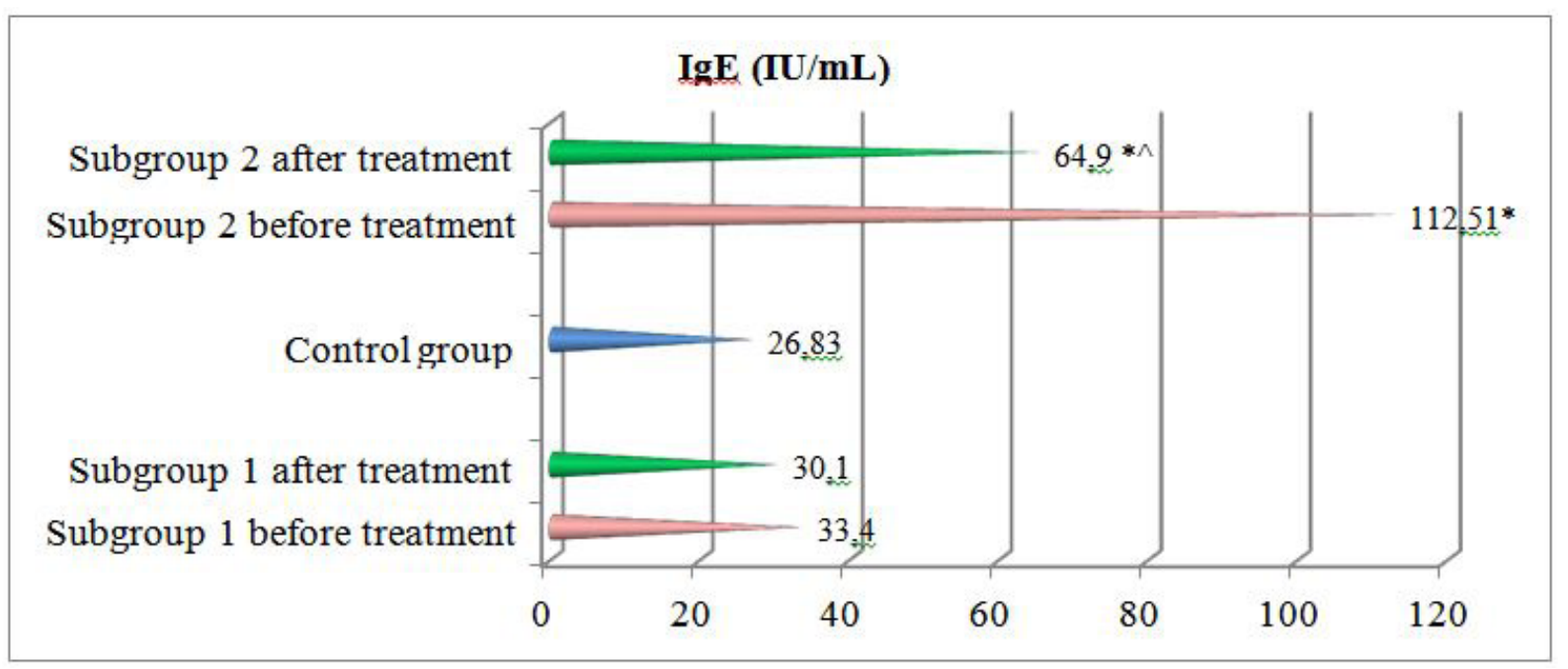

Note: ${ }^{*} \mathrm{p}<0.05$ - statistical significance vs. control group; ${ }^{\wedge} \mathrm{p}<0.05$ - statistical significance of the post-therapy sub- groups vs. pre-therapy sub-groups.

Figure 3: Dynamics of the total IgE level in immunocompromised girls suffering from recurrent NCVV with underlying combined immunotherapy

Figure 3 shows that in girls with concomitant NCVV and atopic dermatitis in 1 subgroup (64\% of cases), the serum IgE level were within control and in the subgroup 2 (36\% of cases), a high IgE level was noted. Combined immunotherapy led to a decrease in IgE in children of the 2 nd subgroup and no changes in IgE levels in children of subgroup 1 . We think that serum IgA, IgG, IgM deficit facilitates continuous inflammation and creates the ground for frequent NCVV relapses with short periods between relapses, marked or unclear clinical manifestations. IgE-dependant and IgE-dependant mechanisms of atopy formation are activated due to overload with infective and non-infective antigens. When assessing the phagocytal function of NG in girls with NCVV, we noted 1.4 -fold reduction in neutrophil phagocytic rate (\% PAN) $(44.86[39 ; 51] \%$ vs. $61.08[53.8 ; 68.8] \%$ in control group, p<0.05). The absorbing ability of NGs tended to reduce: phagocyte number and phagocyte index $(\mathrm{p}>0.05)$. At the same time the digestion and phagocytosis completeness $(\% \mathrm{D}$, ID) did not differ from control group ( $\mathrm{p}>0.05)$. NADPH-oxidase activity assessed using spontaneous NBT test is significantly increased (3.9-fold); it is an adequate response of NGs to an inflammation. Additional antigenic load revealed depletion of the oxygen-dependant NG reserves in the test group manifesting itself in the lack of NADPH oxidase response to St. aureus (CM $1.31[0.83 ; 1.5]$ vs. $2.46[1.65 ; 2.38]$ in control group, p<0.05) (Figure 4). Defective functioning of the first line emergency response, i.e. NG system, does not simulate timely arrest of an inflammation and may cause frequent 
NCVV relapses; it shroud be taken into account When setting the plan of diagnostics and therapy for girls with this pathology.

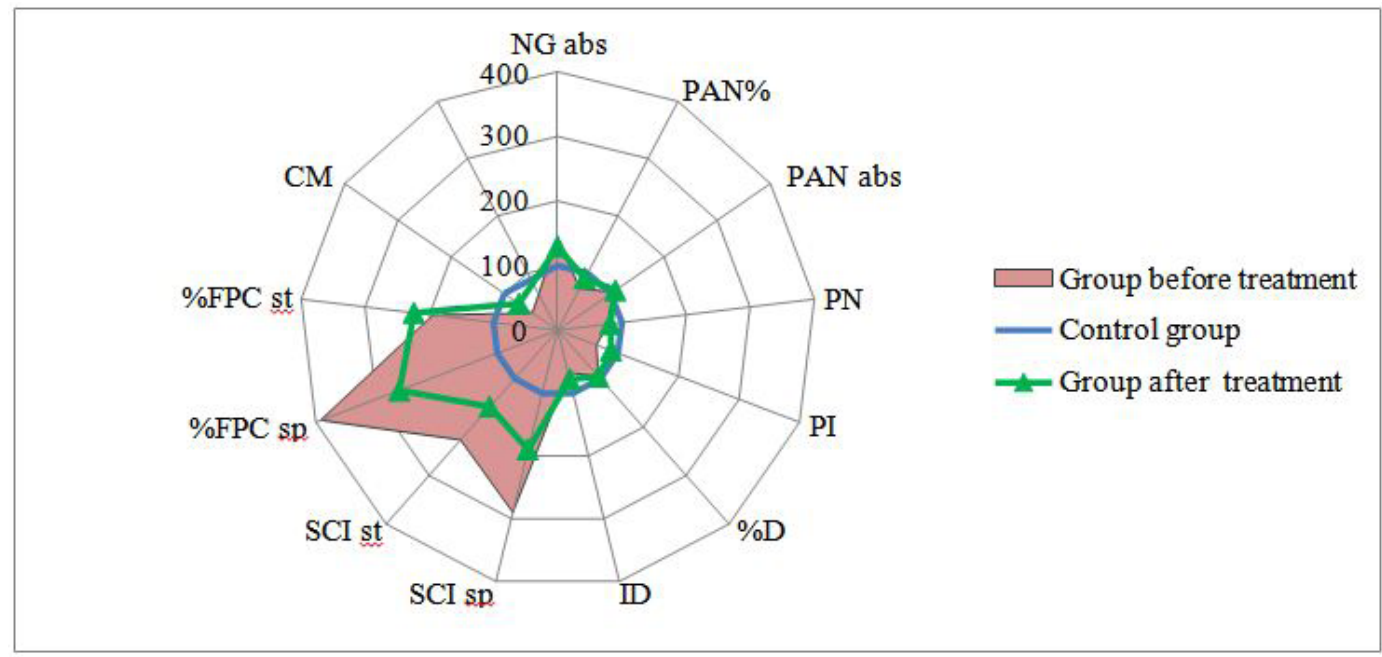

Figure 4: Phagocytal and microbicidal function of neutrophilic granulocytes in immunocompromised girls suffering from NCVV with underlying combined immunotherapy (percent of the control group)

Figure 4 shows the decrease in actively phagocytizing NG (PAN \%), the parameters of capture processes (phagocyte number PN, phagocyte index - PI) against the background of lack of digestion ability of NG (\% digestion - \%D and digestion index - ID), increase in activity of NADPH oxidases in a spontaneous NBT test (\% FPCsp) and depletion of NG reserve capacities to mobilize their oxygen mechanisms when loaded with a bacterial antigen (CM reduction) immunocompromised girls with recurrent NCVV. After the treatment, the normalization of PAN\%, PN, PI and CM was noted with a moderate increase in \% FPC in a spontaneous and stimulated NBT test relative to control (restoration of phagocytosis and reserve NG recovery to mobilization of NADPN oxidase activity).

When the interferon status in the test group was assessed it was found out that IFNa level was reduced (1.8-fold) 5.75 [2.23; 13.56] $\mathrm{pg} / \mathrm{mL}$ vs. $10.56[4.46 ; 15.35] \mathrm{pg} / \mathrm{mL}$ in control group $(\mathrm{p}>0.05)$, whereas IFN $\gamma$ level was 3.37 [0; 11.37] pg/mL, i.e. 2.98 times higher than in the control group $1.13[0 ; 5.71] \mathrm{pg} / \mathrm{mL}(\mathrm{p}>0.05)$ (Figure 5). The data demonstrate inadequate response of the IFN system in immunocompromised girls suffering from relapsing ARVI, lack of adequate increase in serum IFNa, IFN $\gamma$ during relapsing ARVI with the frequency of over 10 Times per year.

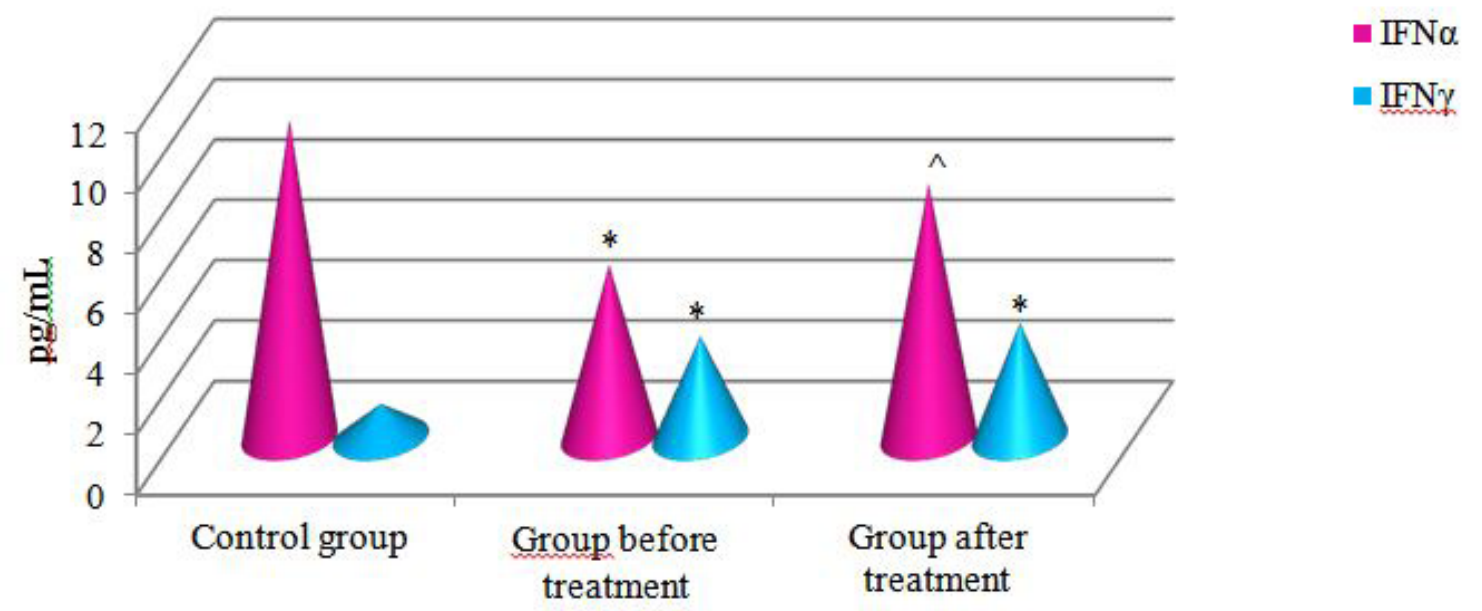

Note: ${ }^{\star} \mathrm{p}<0.05$ - statistical significance vs. control group; ${ }^{\wedge} \mathrm{p}<0.05$ - statistical significance of the post-therapy group vs. pre-therapy group. Figure 5: IFN system in immunocompromised girls suffering from NCVV with underlying combined immunotherapy

Figure 5 shows that immunocompromised girls with HNVV showed a decrease in the level of IFNa and an increase in IFN $\gamma$ - an inadequate response of the IFN system to frequent recurrent ARVI and exacerbations of NCVV. After the treatment, there is an increase in the level of IFNa relative to the start of treatment, while the level of IFN $\gamma$ remains above the control - positive dynamics in the IFN system against the background of a positive clinical effect.

Thus, immunocompromised girls suffering from NCVV have deficit of cytotoxic T lymphocytes, NKC, serum IFNa, IFN $\gamma$, IgA, $\operatorname{IgM}, \mathrm{IgG}$, and defective phagocytal function of NG. It should be pointed out that the above disorders in IS functioning were revealed during NCVV exacerbation, but there were no clinical signs of ARVI. This information witnesses the lack of an adequate 
immune response to existing nonspecific inflammation. Defective IS functioning is a reason for frequent NCVV relapses and relapsing ARVI.

Taking into account the found defects in IS functioning and IFN status in immunocompromised girls, we have developed a program of combined immunotherapy lasting for 2.5 months using local and system therapy with recombinant human interferon a2b combined with antioxidants (Viferon) and glucosaminylmuramyldipeptide (Licopid), which will be included into therapy to a limited extent. Combined IFN and immunotherapy has already proven to be a good choice for immune system rehabilitation in immunocompromised children with age-related ARVI [3,5,6] (Table 1).

\begin{tabular}{|c|c|}
\hline Objective & Therapy scheme \\
\hline $\begin{array}{l}\text { IFN status correction } \\
\text { and modulation }\end{array}$ & $\begin{array}{l}\text { Basic system therapy with recombinant human IFNa2b in combination with antioxidants (Viferon): } \\
\text { Viferon 150,000 U } 1 \text { suppository once daily in the morning and 500,000 U } 1 \text { suppository once daily before going to bed - } 20 \text { days, } \\
\text { then Viferon 500,000 U } 1 \text { suppository once daily - } 20 \text { days, then Viferon } 150,000 \mathrm{U} 1 \text { suppository twice daily }-20 \text { days, then } \\
\text { Viferon } 150,000 \mathrm{U} 1 \text { suppository once daily - } 20 \text { days. } \\
\text { Local therapy with recombinant human IFNa2b in combination with antioxidant (Viferon gel) - smearing 3-4 times daily of } \\
\text { nasal passages, }\end{array}$ \\
\hline $\begin{array}{l}\text { Targeted correction } \\
\text { of NG defects }\end{array}$ & $\begin{array}{c}\text { Glucosaminylmuramyldipeptide (Licopid) } 1 \mathrm{mg} / \text { day, two } 10 \text {-day } \\
\text { Courses with a } 2 \text {-week interval. }\end{array}$ \\
\hline
\end{tabular}

Analysis of the clinical efficiency with observation in a catamnesis for 1 year demonstrated that the combined immunotherapy resulted in 3.4-fold reduction in the incidence of NCVV exacerbations, from 6.2 to 1.8 cases a year $(\mathrm{p}<0.05)$; and the exacerbation duration reduced from 12-14 days to 7-8 days. The clinical pattern of NCVV exacerbations after a complex of therapy was characterised by milder symptoms. For instance, prior to the complex therapy with combined immunotherapy the period of exacerbation was associated with marked discomfort in vulva and vagina, vulva hyperaemia and oedema, discharges (whites); after the therapy mild discomfort and hyperaemia in vulva and vagina were recorded. Besides ARVI incidence reduced from 14.8 to 5.2 episodes per year, $\mathrm{p}<0.05$, and their duration shortened from 10-14 days to 5 days, thus reducing the need in antibacterial therapy due to the absence of severe ARVIs. Clinically safe period significantly increased from 6 months to 11 months per year between relapsing ARVIs, and from 9 months to 11.5 months per year between NCVV exacerbation. The therapy resulted in positive clinical effect: reduction in severity, duration of NCVV exacerbations by 4-7 days and the number of NCVV exacerbations with underlying reduced number of ARVI episodes. It is worth mentioning that the combined immunotherapy led to good toleration of therapy, and there were no side effects.

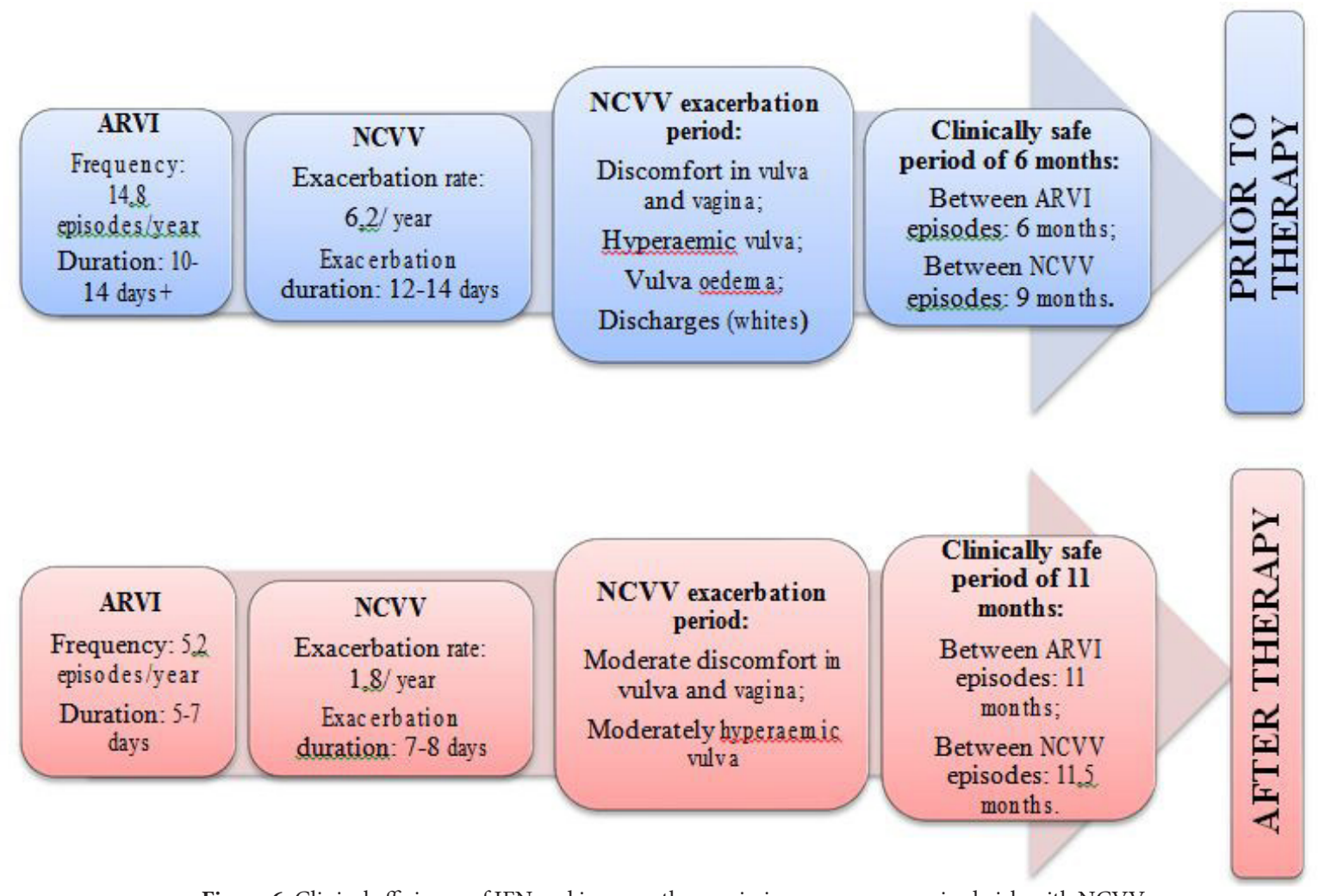

Figure 6: Clinical efficiency of IFN and immunotherapy in immunocompromised girls with NCVV

Positive clinical effects of the combined immunotherapy were accompanied with positive dynamics of changes in IS. The low level of lymphocytes with cytotoxic function $\left(\mathrm{CD} 3^{+} \mathrm{CD}^{+}\right.$; $\left.\mathrm{CD} 3{ }^{-} \mathrm{CD} 16^{+} \mathrm{CD} 56^{+}\right)$normalized, thus leading to restoration of the effector 
function of the anti- infectious immunity (Figure 1). The absolute CD3-CD19+ values normalised as well, causing statistically significant raise in serum IgA, IgG values to the control point which were twice as Low as the standard figure (Figure 1 and 2). Besides, 1.8-2.2-fold reduction in IgE was recorded in 36\% of children with previously elevated IgE (subgroup 2) and constant vs. control group in 64\% of children (subgroup 1) (Figure 3) was revealed. Analysis of phagocytal and microbicidal function of neutrophilic granulocytes demonstrated restoration of actively phagocytizing NGs (neutrophil phagocytic rate (\%PAN, PN, PI); and digestive activity (\%D, ID) (Figure 4). The reserve abilities of NGs recovered which manifested themselves in raised CM with underlying constant moderately elevated NADPH oxidase activity during spontaneous and induced NBT test (Figure 4). These changes are positive, but they demonstrate persistent stress in microbicidal NG systems because of a long-lasting antigen load (infectious antigens, allergenic agents), thus requiring attention and rehabilitation facilitating complete NG dysfunction correction.

The combined immunotherapy allowed seeing the tendency to elevation in IFNa level to 8.45 [4.93; 10.92] pg/mL vs. 10.56 [4.46; $15.35] \mathrm{pg} / \mathrm{mL}$ in control group, at the same time INF- $\gamma$ level did not change 3.81 [0.07; 7.54] (Figure 5). It is worth noting that this effect was demonstrated with absent NCVV exacerbation and with inactive ARVI. These changes in the INF status may be interpreted as positive because previously found deficient IFNa, IFN $\gamma$ production with underlying acute and relapsing inflammations was compensated after the therapy by restoration both in IFN producing cells and in the IFN levels; it being clinically accompanied by the reduction in the frequency and severity of genital and respiratory inflammations [11-15].

\section{Conclusions}

1. The immunonosotropic characteristics impacting NCVV occurrence and formation associated with relapsing ARVIs and atopies in immunocompromised girls, which condition resistivity to the traditional therapy, were identified.

2. A program of combined immunotherapy was developed which took into account the disorders found in the virusinduced immunity, defective NG functioning, deficient serum IgA, IgM, IgG, deficient functioning in the IFN system, for immunocompromised girls suffering from recurrent NCVV and relapsing ARVIs.

3. The developed combined immunotherapy program including Viferon and Licopid made it possible to ensure the positive clinically immunologic and protective effect (observation in a catamnesis for 1 year) in immunocompromised girls suffering from recurrent NCVV and relapsing ARVIs.

4. The combined immunotherapy program demonstrated safety of use in $100 \%$ of cases.

\section{References}

1. Nesterova IV, Malinovskaya VV, Tarakanov VA, Kovaleva SV (2004) INF and immunotherapy in the therapy of children and adults who get ill frequently and for long periods of time. CapricornPublishing Inc. USA, UK, Russia 158.

2. Nesterova IV, Kovaleva SV, Kolesnikova NV, Kleshchenko EI, Shinkareva ON, Chudilova GA, Lomtatidze LV, Kokova LN (2013) Optimization of interferonand immunotherapy in immunocompromised children with associated viral infections. Allergy, asthma \& immunophysiology: from basic science to clinical management. - MEDIMOND International Proceedings 101-4.

3. Bumbulienè Z, Ven clavi ciut e K, Ramasauskaite D, Arlauskien è A, Bumbul E, et al. (2014) Microbiological findings of vulvovaginitis in prepubertal girls. Postgrad Med J 90: 8-12.

4. Šikanić-Dugić N, Pustišek N, Hiršl-Hećej V, Lukić-Grli ć A (2009) Microbiological findings in prepubertal girls with vulvovaginitis. Acta Dermatovenerol Croat $17: 267-72$.

5. Be yit ler İ, Kavukcu S (2017) Clinical presentation, diagnosis and treatment of vulvovaginitis in girls: a current approach and review of the literature. World J Pediatr 13: 101-5.

6. Fischer G (2010) Chronic vulvitis in pre-pubertal girls. Australas J Dermatol 51: 118-23.

7. Gurkin YA (2009) A case of staged therapy of nonspecific vulvovaginites in girls. Pediatric and Adolescent Reproductive Health 5: 15-20.

8. Olejek A, Kellas-Sleczka S, Kozak-Darmas I, Bilska A, Zamłyński J, et al. (2009) Vulvovaginitis in young girls. Ginekol Pol 80: 931-4.

9. Uvarova EV, Batyrova ZK (2012) Physiology and pathology of genitals in young girls. Pediatric and Adolescent Reproductive Health 4: 35-50.

10. Nesterova IV, Sepiashvili RI (2000) Immunologic drugs and modern immunotherapy in clinical immunology in medicine. Allergology and Immunology 3: $18-28$.

11. Beyrau M, Bodkin JV, Nourshargh S (2012) Neutrophil heterogeneity in health and disease: a revitalized avenue in inflammation and immunity. Open Biol 2: $120-34$.

12. Nesterova IV (2016) IFNs in clinical practice: best friends or foes? Allergology and Immunology 17: 189-91.

13. Nesterova IV, Kovaleva SV, Chudilova GA, Lomtatidze LV, et al. (2014) Optimisation in the tactics of INF and immunotherapy in rehabilitation of immunocompromised children with relapsing respiratory and genital viral infections. Paediatrics 93: 66-72.

14. Nesterova I, Klethshenko E, Alekseeva O, Sepiashvili YaR (2011) Interferons and viruses: defense and attack. Interferon and immunotherapy in counterdefense against recurrent and latent viral and bacterial infections. In book: Allergy, asthma, immunology: from genes to clinical applications. Editor R.Sepiashvili Publishing house: MEDIMOND International Proceeding Italy 237-42.

15. Nesterova IV, Kovaleva SV, Chudilova GA, Lomtatidze LV, Malinovskaj VV (2015) The positive transformation of the phenotype, the functional activity of neutrophilic granulocytes in children with recurrent respiratory infections as treatment results of interferon and immunomodulation therapy. Allergy, asthma \& immunophysiology: Recent Advances in Understending and Management. - MEDIMOND International Proceedings 69-72. 


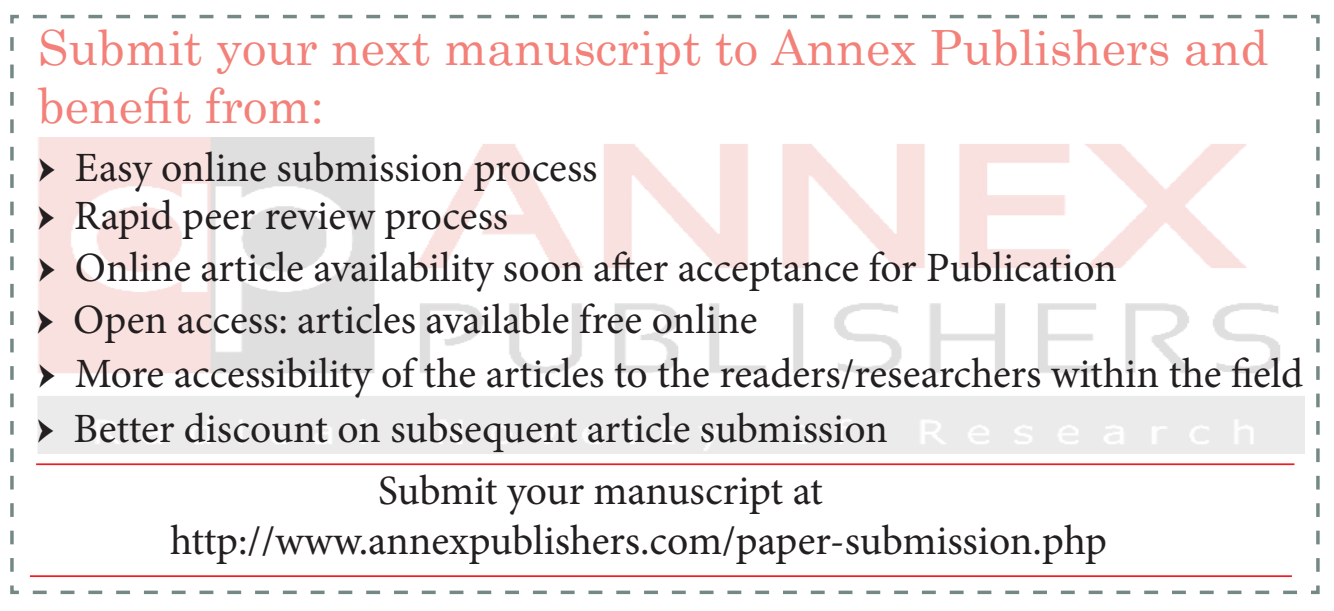

